\title{
UV-B RADIATION EFFECTS ON PHOTOSYNTHESIS, GROWTH AND CANNABINOID PRODUCTION OF TWO Cannabis sativa CHEMOTYPES
}

\author{
John Lydon ${ }^{2 *}$, Alan H. Teramura ${ }^{1}$ and C. Benjamin Coffman ${ }^{3}$ \\ 'Department of Botany, University of Maryland, College Park, MD 20742, USA, ${ }^{2}$ USDA-ARS, \\ Southern Weed Science Laboratory, P.O. Box 350. Stoneville, MS 38776, USA and 'USDA-ARS \\ Weed Science Laboratory, AEQ. I, Beltsville. MD 20705. USA
}

(Received 29 August 1986; accepted 24 February 1987)

\begin{abstract}
The effects of UV-B radiation on photosynthesis, growth and cannabinoid production of two greenhouse-grown $C$. sativa chemotypes (drug and fiber) were assessed. Terminal meristems of vegetative and reproductive tissues were irradiated for 40 days at a daily dose of $0,6.7$ or $13.4 \mathrm{~kJ}$ $\mathrm{m}^{-2}$ biologically effective UV-B radiation. Infrared gas analysis was used to measure the physiological response of mature leaves, whereas gas-liquid chromatography was used to determine the concentration of cannabinoids in leaf and floral tissue.

There were no significant physiological or morphological differences among UV-B treatments in either drug- or fiber-type plants. The concentration of $\Delta^{y}$-tetrahydrocannabinol ( $\Delta^{y}$-THC), but not of other cannabinoids, in both leaf and floral tissues increased with UV-B dose in drug-type plants. None of the cannabinoids in fiber-type plants were affected by UV-B radiation.

The increased levels of $\Delta^{\prime \prime}$-THC in leaves after irradiation may account for the physiological and morphological tolerance to UV-B radiation in the drug-type plants. However, fiber plants showed no comparable change in the level of cannabidiol (a cannabinoid with UV-B absorptive characteristics similar to $\Delta^{\prime \prime} \mathrm{THC}$ ). Thus the contribution of cannabinoids as selective UV-B filters in $C$. sativa is equivocal.
\end{abstract}

\section{INTRODUCTION}

Cannabis sativa $\mathrm{L}$. contains a number of secondary metabolites (cannabinoids) that are species specific. Although the biosynthetic pathway of the major cannabinoids has been established (Mechoulam, 1970; Shoyama et al., 1984), the regulation of cannabinoid production remains unsolved. Some researchers contend that cannabinoid production is genetically controlled and uninfluenced by environmental factors (Doorenbos et al., 1971; Fetterman et al., 1971). Other studies indicate that although the primary control appears to be genetic, cannabinoid production can be modified by an environmental component (Haney and Kutscheid, 1973; Latta and Eaton, 1975; Turner et al., 1982).

Although the mechanism is unknown, a relationship exists between cannabinoid content and the altitude at which $C$. sativa is grown. Mobark et al. (1978) suggested that the high-altitude environment

\footnotetext{
*To whom correspondence should be addressed.

Ab breviations: $A, \mathrm{CO}_{2}$ assimilation; $\mathrm{CA}$, cellulose acetate; $C_{\mathrm{a}}$, ambient $\mathrm{CO}_{2} ; \mathrm{CBC}$, cannabichromene; $\mathrm{CBD}$, cannabidiol; $\mathrm{CBDA}$, cannabidiolic acid; $\overline{\mathrm{CBG}} \overline{\mathrm{B}}$, cannabigerol; CBN, cannabinol; CBNA, cannabinolic acid; DW, dry weight; $E$, transpirational water loss; $g_{\text {, }}$, leaf conductance to water vapor; PPFD, photosynthetic photon flux density between $400-700 \mathrm{~nm} ; R_{\mathrm{d}}$. dark respiration; $\Delta^{*}$. THC, $\Delta^{8}$-tetrahydrocannabinol; $\Delta^{y}$-THC, $\Delta^{y}$-tetrahydrocannabinol; $\Delta^{\mathrm{x}}$-THCA,$\Delta^{\mathrm{*}}$-tetrahydrocannabinolic acid; $\Delta^{9}$-THCA, $\Delta^{9}$-tetrahydrocannabinolic acid; UV-B, radiation between $280-320 \mathrm{~nm}$; UV-B $B_{B E}$, biologically effective UV-B; VPD, vapor pressure deficit.
}

was responsible for an increased production of propyl cannabinoids in plants grown at $1300 \mathrm{~m}$. The average total cannabinoid content of wild, mature (flowering) Indian C. sativa from elevations between $250 \mathrm{~m}$ and $1000 \mathrm{~m}$ was $2.43 \%$ (by dry wt); between $1000 \mathrm{~m}$ and $2000 \mathrm{~m}$ was $3.01 \%$; and above $2000 \mathrm{~m}$ was $1.39 \%$ (Turner et al., 1979). The cannabinoid content in four out of five of these mature Indian $C$. sativa variants decreased when grown at sea level in Mississippi, USA.

One likely factor which may be of significance to cannabinoid production in both high-altitude and tropical environments is ultraviolet radiation. Measurements made in Utah showed that the biologically effective ultraviolet-B radiation flux (UV$B_{B E} 280-320 \mathrm{~nm}$, weighted with a generalized plant response function, Caldwell, 1971) at $3350 \mathrm{~m}$ is $32 \%$ greater than at $1500 \mathrm{~m}$ (Caldwell et al., 1980). Latitudinal variations of solar UV-B radiation are also considerable. Numerous studies have shown the deleterious effects of UV radiation on many unrelated plant species (for reviews see Caldwell, 1971; Klein, 1978; Teramura, 1983). Tolerance to UV-B radiation in some plants has been attributed to their ability to produce secondary metabolites, such as flavonoids, which absorb and prevent actinic UV-B radiation from penetrating plant tissues (Caldwell et al., 1983; Flint et al., 1985). Cannabinoids in fresh plant tissue are in the form of acids (Doorenbos et al., 1971) that strongly absorb UV$B$ radiation, making these compounds likely candidates as solar screens. 
Pate (1983) reported that $C$. sativa populations originating from high UV-B environments contained little or no cannabidiol (CBD) but high levels of $\Delta^{9}$-tetrahydrocannabinol $\left(\Delta^{9}-T H C\right)$, while the opposite was true for populations from low UV-B environments, and proposed that the two distinct C. sativa chemotypes (drug and fiber) evolved as a result of selective pressures brought about by UV-B radiation.

Fairbairn and Liebmann (1974) reported that the $\Delta^{9}$-THC content of leaf tissue from UV irradiated greenhouse-grown drug-type $C$. sativa was $23 \%$ greater than non-irradiated greenhouse-grown plants. However, neither the spectral distribution nor the daily dose of UV radiation were reported.

The objectives of this study were to test: (a) The physiological and morphological insensitivity of both the drug- and fiber-types of $C$. sativa to UV$B$ radiation; and (b) to correlate this insensitivity with a change in production of $\Delta^{9}-\mathrm{THC}$ or CBD in drug- and fiber-type plants, respectively.

\section{MATERIALS AND METHODS}

Two populations of pistillate Cannabis sativa $L$.. one a high $\Delta^{9}$-THC producing drug-type of Jamaican origin and the other a high CBD producing fiber-type of Czechoslovakian origin were cloned from vegetative cuttings as described by Coffman and Gentner (1979) in a greenhouse located at USDA, Beltsville, MD. Rooted cuttings were transferred to $0.6-\ell$ plastic pots containing Metromix 300 potting mixture (composed of composted bark, peat moss, vermiculite, perlite, granite, and sand) and watered daily, alternating between tap water and a dilute solution of Peters $20-20-20$ general purpose fertilizer providing 7.3 $\mathrm{mmol} \mathrm{N}, 0.7 \mathrm{mmol} P$ and $1.0 \mathrm{mmol} \mathrm{K}$ per pot. To prevent root binding, approximately every two months plants were transferred to successively larger pots with an additional $0.3-\ell$ vol. Vegetative or flowering plants were exposed to UV-B radiation for 30 days prior to the start of the experiment. At that time, plants were trimmed to a uniform height. Vegetative and floral meristems developed while plants were irradiated for an additional 40 days.

UV-B radiation was suplied by filtered Westinghouse FS-40 sunlamps as described by Mirecki and Teramura (1984). All lamps were fitted with either presolarized 0.08 or $0.13 \mathrm{~mm}$ cellulose acetate (UV-B transmitting) or 0.13 mm Mylar Type S (control) filters. Treatments were separated by $0.26 \mathrm{~mm}$ Mylar shields. Individual plant heights were adjusted to maintain a uniform canopy, while the lamp/plant distance was maintained at $0.25 \mathrm{~m}(0.08 \mathrm{~mm}$ CA filtered lamps) or $0.35 \mathrm{~m}$ ( $0.13 \mathrm{~mm} \mathrm{CA}$ and Mylar filtered lamps). The spectral irradiance was determined with an Optronic Laboratories, Inc. Model 742 Spectroradiometer interfaced with a Hewlett Packard 85 printing calculator, and weighted with a generalized plant action spectrum (UV-B $\mathrm{B}_{\mathrm{BE}}$, Caldwell, 1971), normalized at 300 $\mathrm{nm}$. Ultraviolet-B radiation was provided for $3 \mathrm{~h}$ on either side of solar noon, resulting in a daily UV- $B_{\mathrm{BE}}$ dose of 0 , 6.7 , or 13.4 effective $\mathrm{kJ} \mathrm{m}^{-2} \mathrm{UV}-\mathrm{B}_{\mathrm{BE}}$. The highest dose was equivalent to the daily weighted UV-B dose received under clear sky conditions and minimum solar zenith in Colombia, South America $\left(0^{\circ}\right.$ latitude, $3 \mathrm{~km}$ elevation, Julian date 80 , Green et al., 1980). There was no natural solar contribution to the daily UV-B $B_{B E}$ dose due to the absorptivity of greenhouse glass.

Vegetative drug-type plants (10 plants per treatment) were exposed to UV-B radiation during the months of November and December 1983 when the plants were 9 months old; average total daily photosynthetic photon flux density (PPFD between $400-700 \mathrm{~mm}$ ), recorded with a LICOR LI-550 printing calculator equipped with a LI-COR $\mathrm{LI}-185$ quantum sensor, was $11.4 \mathrm{~mol} \mathrm{~m}^{-2}$, and average daily maximum/minimum air temperature were $25 / 20^{\circ} \mathrm{C}$. The natural photoperiod was extended to $16 \mathrm{~h}$ with a $1000 \mathrm{~W}$ General Electric $\mathrm{Hg}$ vapor lamp to inhibit flowering. Reproductive drug-type plants $(10$ plants per treatment) were irradiated during the months of February and March 1984 when the plants were 11 months old, the average total daily PPFD was $13.5 \mathrm{~mol} \mathrm{~m}^{-2}$, and average daily maximum $/$ minimum air temperatures were $28 / 23^{\circ} \mathrm{C}$. Reproductive fiber-type plants (10 plants per treatment) were irradiated during the months of November and December 1984 when the plants were 9 months old, average total daily PPFD was $10.7 \mathrm{~mol} \mathrm{~m}^{-2}$, and average daily maximum/minimum air temperatures were $29 / 20^{\circ} \mathrm{C}$, while vegetative fiber-type plants ( 8 plants per treatment) were irradiated during the months of April and May 1985 when the plants were 13 months old, average total daily PPFD was $21.2 \mathrm{~mol} \mathrm{~m}^{-2}$, and average daily maximum/minimum air temperatures were $28 / 23^{\circ} \mathrm{C}$. Thus, data for vegetative and reproductive tissues (within a chemotype) were collected from the same plants at different developmental stages.

After the 40-day irradiation period, $\mathrm{CO}_{2}$ assimilation $(A)$, transpirational water loss $(E)$, dark respiration $\left(R_{\mathrm{d}}\right)$, and leaf conductance to water vapor $\left(g_{\mathrm{s}}\right)$ were measured on single, fully expanded, attached leaves in temperaturecontrolled cuvettes in an open gas exchange system using a dual gas detector Anarad 600R infrared gas analyzer. Gas exchange measurements for drug-type plants were conducted at an ambient $\mathrm{CO}_{2}$ concentration $\left(C_{\mathrm{i}}\right)$ of 340 $\pm 6 \mu \ell \ell^{-1}$. Air was bubbled through water at $18^{\circ} \mathrm{C}$ and circulated over a leaf maintained at $28^{\circ} \mathrm{C}$, resulting in an average leaf-to-air vapor pressure deficit (VPD) of 1.45 $\pm 0.03 \mathrm{kPa}$. The flux of $\mathrm{H}_{2} \mathrm{O}$ vapor was measured with an EG\&G Model 911 and a General Eastern Systems 1100 DP condensation dew point hygrometer located immediately before and after the leaf chamber. Natural insulation was supplemented with a General Electric $1000 \mathrm{~W} \mathrm{Hg}$ vapor lamp to provide saturating irradiances of $1500 \mu \mathrm{mol}$ $\mathrm{m}^{-2} \mathrm{~s}^{-1}$ (measured with a LI-COR LI-185 quantum sensor). Gas exchange measurements for the fiber-type plants were conducted at similar conditions except $C_{i}$ was $310 \pm 2 \mu \ell \ell^{-1}$ and VPD was $1.84 \pm 0.03 \mathrm{kPa}$. To correct for differences in $C_{a}$ and VPD of drug- and fiber-type plants at the time of measurement, reported $A$ and $E$ data for fiber-type plants were standardized for average intercellular $\mathrm{CO}_{2}$ and VPD values of drug-type plants (i.e. $235 \mu \ell \ell^{-1}$ and $1.45 \mathrm{kPa}$, respectively). Carbon dioxide assimilation and $E$ were calculated in a manner similar to that described by Nobel (1976). Leaf conductance to water vapor $\left(g_{s}\right)$ was calculated following conventional resistance analyses using 1.56 as the coefficient relating the diffusivities of $\mathrm{CO}_{2}$ and water vapor (Nobel, 1976).

The photosynthetic light response was determined at a uniform temperature $\left(28^{\circ} \mathrm{C}\right)$ by covering the leaf cuvette with successive layers of cheesecloth and ultimately covering the cuvette with a light-tight cloth for estimates of $R_{\mathrm{d}}$. The temperature response of photosynthesis was determined at a saturating PPFD of $1500 \mu \mathrm{mol} \mathrm{m} \mathrm{m}^{-2} \mathrm{~s}^{-1}$ by increasing leaf temperature (via cuvette air temperature) by $1 \pm 0.2^{\circ} \mathrm{C}$ from 26 to $32^{\circ} \mathrm{C}$. Both light saturation and temperature response of photosynthesis were measured on attached, mature leaves which expanded while irradiated with a daily UV-B $B_{B E}$ dose of either 0 or 13.4 effective $\mathrm{kJ} \mathrm{m}^{-2}$ (one leaf per plant, three plants per treatment, and two treatments, $N=6$ ).

Samples for cannabinoid analysis were harvested after 40 days of irradiation at the same time of day $(3 \mathrm{~h}$ after solar noon) to avoid sample differences due to possible diurnal fluctuations in cannabinoid content (Turner et al., 1975 ) lyophilized, and stored at $-5^{\circ} \mathrm{C}$. Five hundred milli- 


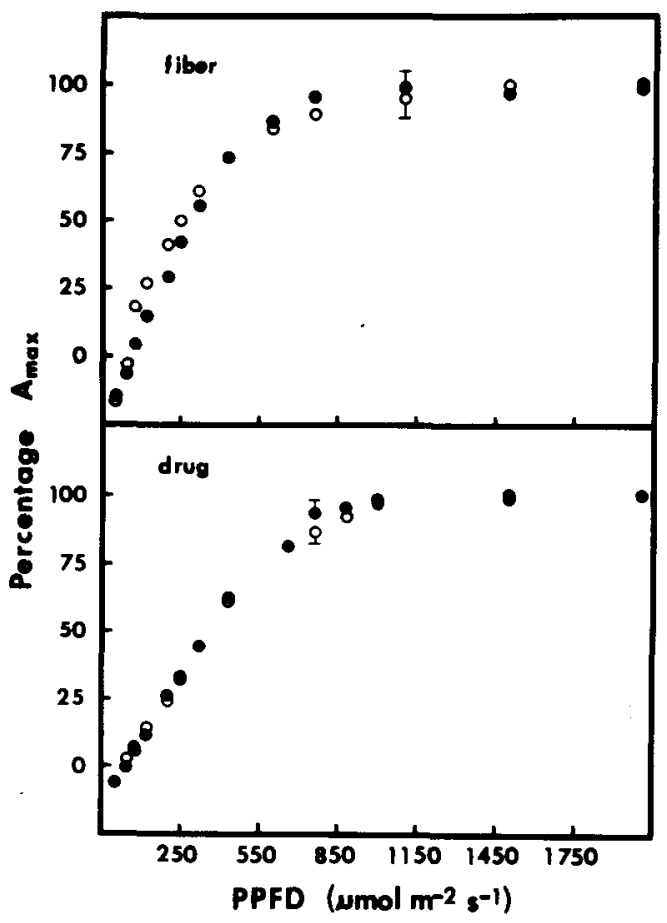

Figure 1. The effects of photosynthetic photon flux density (PPFD, $400-700 \mathrm{~nm}$ ) on $\mathrm{CO}_{2}$ assimilation of fiber-type and drug-type Cannabis sativa irradiated with a daily UV$\mathrm{B}_{\mathrm{BE}}$ dose of $0(\mathrm{O})$ and $13.4(0)$ effective $\mathrm{kJ} \mathrm{m}^{-2}$. Vertical lines represent $\pm 1 \mathrm{SE}$.

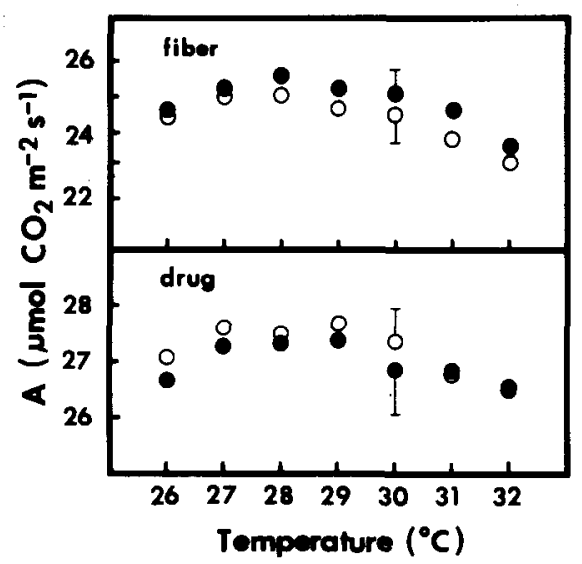

Figure 2. The effects of temperature on $\mathrm{CO}_{2}$ assimilation of fiber-type and drug-type Cannabis sativa irradiated with a daily $\mathrm{UV}-\mathrm{B}_{\mathrm{BE}}$ dose of $0(\mathrm{O})$ and $13.4(0)$ effective $\mathrm{kJ}$ $\mathrm{m}^{-2}$. Vertical lines represent \pm 1 SE.

grams of floral tissue (or $100 \mathrm{mg}$ leaf tissue) were ground in a mortar with pestle and extracted in $100 \mathrm{~m} \ell$ chloroform for $24 \mathrm{~h}$ with sonication at 0,12 and $24 \mathrm{~h}$. The extract was then filtered, evaporated to dryness under vacuum at room temperature, redissolved in $1 \mathrm{~m} \ell$ hexane containing $5 \mu \mathrm{g}$ $\mu \ell^{-1}$ of $n$-hexacosane (the internal standard) and centrifuged at $30000 \mathrm{~g}$ for $10 \mathrm{~min}$ before analysis by gas chromatography.
Chemical analysis of the supernatant was performed using a Varian 3700 gas-liquid chromatograph (with a Varian CDS 401 data processor) equipped with a hydrogen flame-ionization detector and a $6.4 \mathrm{~mm} \mathrm{OD,} 2 \mathrm{~mm}$ ID by $2.43 \mathrm{~m}$ glass column packed with $3 \% \mathrm{SP}-2100$ on $100 / 120$ mesh Supelcoport. The inlet and detector temperatures were 240 and $260^{\circ} \mathrm{C}$, respectively, while the column was operated isothermally at $190^{\circ} \mathrm{C}$. Helium was the carrier gas flowing at $0.33 \mathrm{~m}^{-1} \mathrm{~s}^{-1}$. The system was calibrated using varying concentrations of the following pure standards (purchased from Applied Sciences) dissolved in $n$-hexane containing $5 \mu \mathrm{g} \mu \ell^{-1} n$-hexacosane: $\Delta^{y}$-THC, $\Delta^{4}$-THC, $\mathrm{CBD}$, cannabichromene (CBC), cannabinol (CBN) and cannabigerol (CBG). Cannabinol and $\mathrm{CBG}$ co-chromatograph and were calibrated as the combined peak. Results were expressed as $\mathrm{mg}$ cannabinoid $\mathrm{g}^{-1}$ dry weight (DW) leaf or floral tissue.

A comparison among treatments was made with analysis of variance with three treatments, eight or ten plants per treatment, and the average of three replicate samples per plant $(N=24$ or 30 , Kleinbaum and Kupper, 1978). Linear regression analysis was used where UV-B treatment effects were found to be significant $(P<0.05)$ by analysis of variance.

\section{RESULTS}

Light saturation of $\mathrm{CO}_{2}$ assimilation $(A)$ in the drug- and fiber-type controls occurred at PPFDs greater than $850 \mu \mathrm{mol} \mathrm{m} \mathrm{m}^{-2} \mathrm{~s}^{-1}$ (Fig. 1). There was no significant difference in $A$ from 26 to $32^{\circ} \mathrm{C}$ in either clone, although $A$ tended to decrease at temperatures $>30^{\circ} \mathrm{C}$ (Fig. 2). The light and temperature response of $A$ and $A_{\text {max }}$ were unaffected by UV-B radiation in both drug- and fiber-type plants (Figs. 1 and 2). Data on the physiological and morphological parameters of the drug- and fiber-type controls are presented in Table 1. None of these physiological parameters were significantly affected by UV-B radiation in either chemotype (data not shown).

The cannabinoid levels and profiles of the drugand fiber-type controls (Table 1) were similar to those reported for other Jamaican and Czechoslovakian populations of $C$. sativa (Holly et al., 1975). The major cannabinoid (CBD) in the fiber-type plants and the minor cannabinoids in drug- and fiber-type plants were not significantly affected by UV-B radiation (data not shown). Only the $\Delta^{9}$-THC content in leaf and floral tissues of drug-type plants increased significantly with UV-B radiation. Regression analyses indicated that there was a significant linear increase in $\Delta^{9}$-THC with UV-B dose in these tissues (Fig. 3). The concentration of $\Delta^{9}$ THC in leaf tissue increased by $22 \%$ and $48 \%$ with a total daily UV-B dose of 6.7 and 13.4 effective $\mathrm{kJ}$ $\mathrm{m}^{-2}$, respectively, as compared to controls. The same levels of UV-B radiation resulted in a $15 \%$ and $32 \%$ increase in $\Delta^{9}-$ THC, respectively, in floral tissues. The $R^{2}$ values, based on regression (see Fig. 3 for equations) about all sample observations were 0.32 and 0.31 for floral and leaf tissues, respectively. However, $R^{2}$ values based on regression about the sample means were 0.99 for both tissues. Thus the regression equations provide a suitable model for UV-B induced $\Delta^{9}$-THC production in these tissues. 
Table 1. Physiology, leaf morphology and cannabinoid production of greenhouse-grown drug- and fiber-type control plants

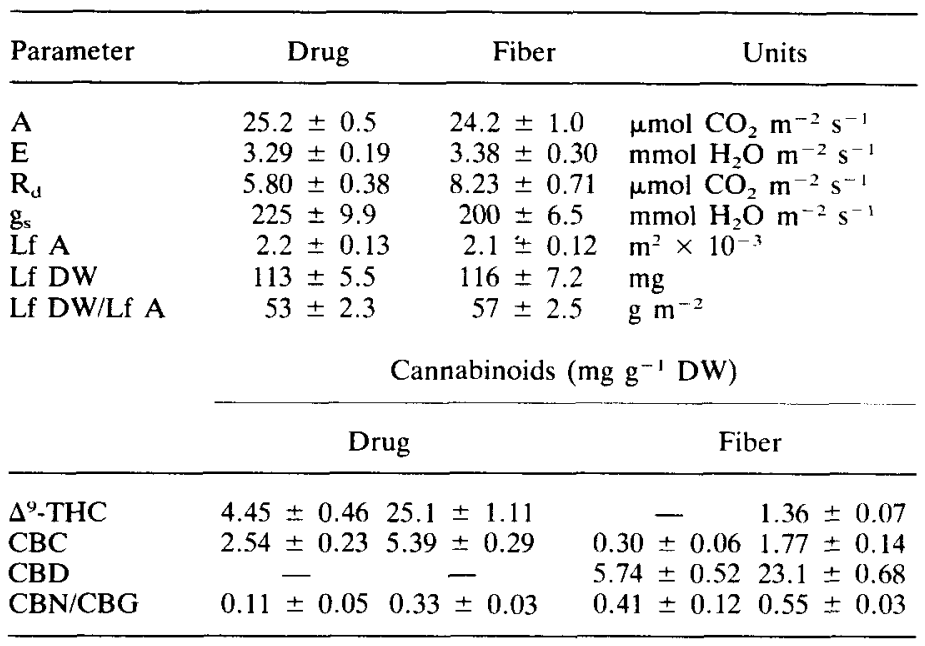

Each value represents the mean of 10 sample means ( 10 plants with 3 subsamples per plant) $\pm 1 \mathrm{SE}$, except for fiber-type vegetative tissue, where each value represents the mean of 8 sample means. $A=\mathrm{CO}_{2}$ assimilation; $E=$ transpiration; $R_{\mathrm{d}}=$ dark respiration; $g_{\mathrm{s}}=$ leaf conductance to water vapor; $\mathrm{Lf} A=$ leaf area; $\mathrm{Lf} \mathrm{DW}=$ leaf dry weight; $\mathrm{Lf} \mathrm{DW} / \mathrm{Lf} \mathrm{A}=$ leaf dry weight to leaf area ratio; $\Delta^{9}$-THC $=\Delta^{9}$-tetrahydrocannabinol; $\mathrm{CBC}=$ cannabichromene; $\mathrm{CBD}=$ cannabidiol $; \mathrm{CBN} / \mathrm{CBG}=$ cannabinol and $/$ or cannabigerol.

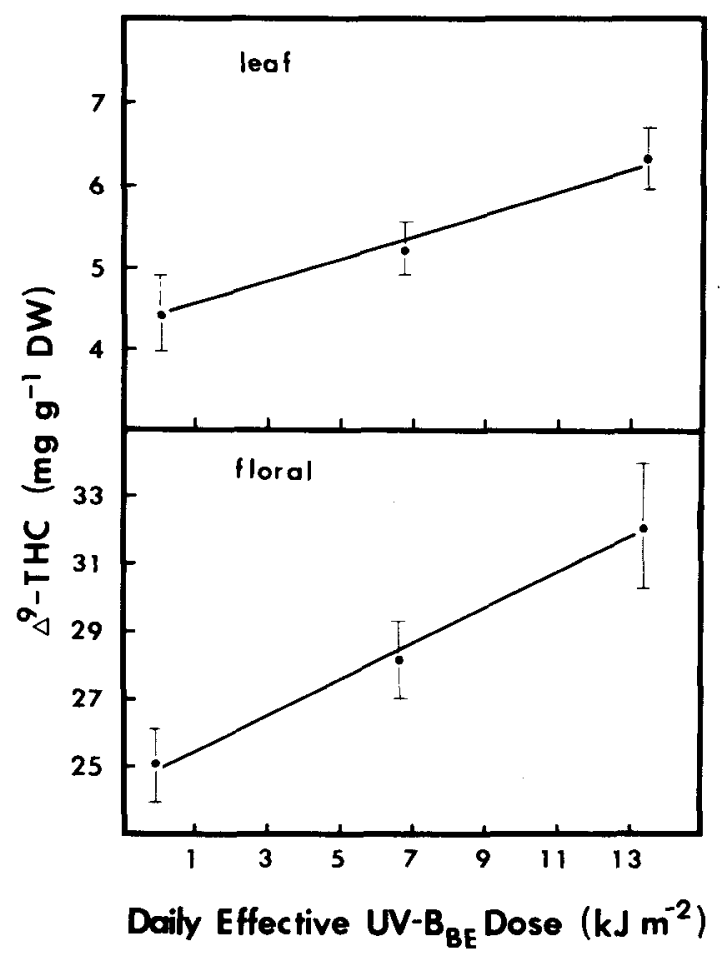

Figure 3. The effects of UV-B radiation on $\Delta^{\prime \prime}$-tetrahydrocannabinol $\left(\Delta^{9}\right.$-THC) content of leaf and floral tissue from drug-type Cannabis sativa. Vertical lines represent $\pm 1 \mathrm{SE}$. Regression equations are: $Y=25.0+0.5149 X$ for floral tissue; and $Y=4.39+0.1402 X$ for leaf tissue.

\section{DISCUSSION}

The chemotypes used in the present study could be representative of tropical (Jamaican) and temperate (Czechoslovakian) populations. $A_{\max }$ and $g_{\mathrm{s}}$ for these populations were within the range reported for other herbaceous $C_{3}$ plants (Korner et al., 1979). Light saturation of photosynthesis in both populations occurred at irradiances typical of plants grown in intermediate PPFDs (Boardman, 1977), which were the approximate conditions in the greenhouse (i.e. about $62 \%$ of ambient, Solar Radiation Measurements 1980-1981, Smithsonian Radiation Biology Laboratory, Rockville, Maryland). In a study of four different populations of $C$. sativa from two distinct climates (tropical and temperate), Bazzaz et al. (1975) reported that all populations had similar photosynthetic light responses, failed to light-saturate and $A_{\max }$ was 7.9 to $9.7 \mu \mathrm{mol} \mathrm{CO}_{2}$ $\mathrm{m}^{-2} \mathrm{~s}^{-1}$ (at 80000 lux). The $A_{\max }$ values reported by Bazzaz et al. (1975) were 2 to 3.5 times lower than those measured in the drug- and fiber-type populations used in this study. The latter is possibly due to differences in the PPFD between their growth chamber study and this greenhouse study.

Pate (1983) reported that $C$. sativa originating from high UV-B environments produced high levels of $\Delta^{9}$-THC and low levels of CBD, while the reverse was true in low UV-B environments. He concluded that $\Delta^{9}$-THC functioned as a UV-B filter, and that 
UV-B radiation was the selective force that resulted in the present distribution of these populations. The results presented here indicate that both types of vegetative $C$. sativa are physiologically and morphologically insensitive to UV-B radiation. The increased level of $\Delta^{9}$-THC found in leaf tissues upon UV-B irradiation may account for this insensitivity in the drug-type plants. However, fiber-type plants showed no comparable change in the level of CBD (which has similar UV-B absorption characteristics). Thus, the contribution of cannabinoids to the UV$B$ insensitivity in vegetative $C$. sativa is equivocal. Perhaps the background levels of CBD present in the fiber-type tissues were sufficient to protect the plant from UV-B radiation. Alternatively, other UV-B absorbing compounds such as flavonoids may account for this UV-B insensitivity. Flavonoids are the principle pigments associated with UV radiation screening in plants (Caldwell et al., 1983; Flint et al., 1985). Barrett et al. (1985) reported that the concentration of Cannflavin A (a flavonoid from $C$. sativa) was similar in drug- and fiber-type leaf tissue, whereas Gellert et al. (1974) reported relatively more flavonoids in drug- than fiber-type plants. Whether the quality and quantity of flavonoids in leaf tissues of the chemotypes in this study were sufficient to account for the observed UV-B insensitivity was not determined.

The results presented in this study, however, do not totally invalidate Pate's hypothesis. Only capitate-sessile and capitate-stalked glands contain cannabinoids, with stalked glands containing $>7$ times more cannabinoids than sessile glands (Mahlberg et al., 1984). Capitate-stalked glands are only present on bracts (and associated leaves), cover over $70 \%$ of the surface area of bracts, and contain $100 \%$ of the cannabinoids in these tissues (Mahlbert et al., 1984). Thus, the UV-B absorbing cannabinoids may be important in preventing this actinic radiation from penetrating ovary tissues. If so, populations of $C$. sativa which express UV-B enhanced cannabinoid production (as demonstrated with the drug chemotype) may have more reproductive success in high UV-B radiation environments. This may account for the distribution of these chemotypes in temperate and tropical environments as reported by Pate (1983). It should be pointed out, however, that one should be cautious when extrapolating from greenhouse to field conditions in UV-B studies. In addition, when considering the distribution of $C$. sativa, one cannot overlook the fact that it is one of the oldest cultivated plants known to man. Thus, its present distribution may possibly be an artifact of man's cultural practices.

In conclusion, the $\Delta^{9}$-THC content in leaf and floral tissues of greenhouse grown drug-type $C$. sativa increased linearly with UV-B dose. Other cannabinoids in drug- and fiber-type plants were unaffected by UV-B radiation. Both drug and fiber chemotypes were physiologically and morphologically tolerant to UV-B radiation. Thus, this tolerance was observed regardless of the concentration or composition of UV-B absorbing cannabinoids. Therefore, it appears that other factors may contribute to the UV-B insensitivity of vegetative $C$. sativa. Nevertheless, the increased production of $\Delta^{9}$-THC in floral tissues (where this compound is most concentrated) of drug-type plants upon UV-B irradiation may result in more reproductive success for drug-type than fiber-type $C$. sativa in high UVB environments as suggested by Pate (1983).

Acknowledgements-This research was supported in part by the Graduate School, University of Maryland, College Park Maryland. The authors would like to thank Dr. S. $O$. Duke for his critical review of the manuscript and the Research Institute of Pharmaceutical Sciences, School of Pharmacy, University of Mississippi for providing seed of the fiber chemotype.

Mention of a trademark, proprietary product or vendor does not constitute a guarantee or warranty of the product by the University of Maryland or the US Department of Agriculture and does not imply its approval to the exclusion of other products or vendors that may also be suitable.

\section{REFERENCES}

Barrett, D. Gordon and F. J. Evans (1985) Isolation from Cannabis sativa $\mathrm{L}$. of cannflavin-a novel inhibitor of prostaglandin production. Biochem. Pharmacol. 34. 2019-2024.

Bazzaz, F. A., D. Dusek, D. S. Seigler and A. W. Haney (1975) Photosynthesis and cannabinoid content of temperate and tropical populations of Cannabis sativa. Biochem. System. Ecol. 3, 15-18.

Boardman, N. K. (1977) Comparative photosynthesis of sun and shade plants. Annu. Rev. Plant Physiol. 28, 355-377.

Caldwell, M. M. (1971) Solar UV irradiance and the growth and development of higher plants. In Photophysiology (Edited by A. C. Giese), Vol. 6, pp. 131-177. Academic Press, New York.

Caldwell, M. M., R. Robberecht and W. D. Billings (1980) A steep latitudinal gradient of solar ultraviolet$\mathrm{B}$ radiation in the arctic-alpine life zone. Ecology 61 , 600-611.

Caldwell, M. M., R. Robberecht and D. Flint (1983) Internal filters: Prospects for UV-acclimation in higher plants. Physiol. Plant. 58, 445-450.

Coffman, C. B. and W. A. Gentner (1979) Greenhouse propagation of Cannabis sativa $\mathrm{L}$. by vegetative cuttings. Econ. Bot. 33, 124-127.

Doorenbos, N. J., P. S. Fetterman, M. M. Quimby and C. E. Turner (1971) Cultivation, extraction and analysis of Cannabis sativa L. Ann. N. Y. Acad. Sci. 191, 3-12.

Fairbairn, J. W. and T. A. Liebmann (1974) The cannabinoid content of Cannabis sativa $\mathrm{L}$. grown in England. J. Pharm. Pharmac. 26, 413-419.

Fetterman, P. S., E. S. Keith, C. W. Waller, O. Guerrero, N. J. Doorenbos and M. M. Quimby (1971) Mississippi-grown Cannabis sativa L.: Preliminary observations on chemical definition of phenotype and variations in tetrahydrocannabinol content versus age, sex and plant part. J. Pharm. Sci. 60, 1246-1249.

Flint, S. D., P. W. Jordan and M. M. Caldwell 
(1985) Plant protective response to enhanced UV-B radiation under field conditions: Leaf optical properties and photosynthesis. Photochem. Photobiol. 41, 95-99.

Gellert, M. I., I. Novak, M. Szell and K. Szendrei (1974) Glycosidic components of Cannabis sativa L. I. Flavonoids. United Nations Secretariat, Scientific Research on Cannabis no. 50, ST/SOA/SER.S/50, pp. $1-8$

Green, A. E., K. R. Cross and L. A. Smith (1980) Improved analytic characterization of ultraviolet skylight. Photochem. Photobiol. 31, 59-65.

Haney, A. and B. B. Kutscheid (1973) Quantitative variations in the chemical constituents of marihuana from stands of naturalized Cannabis sativa L. in Eastcentral Illinois. Econ. Bot. 27, 193-203.

Holly, J. H., K. W. Hadley and C. E. Turner (1975) Constituents of Cannabis sativa L. XI: Cannabidiol and cannabichromene in samples of known geographical origin. J. Pharm. Sci. 64, 892-895.

Klein, R. (1978) Plants and near-UV radiation. Bot. Rev. 44, 1-127.

Kleinbaum, D. G. and L. L. Kupper (1978) Applied Regression Analysis and other Multivariable Methods. Duxbury Press, North Scituate, MA.

Korner, Ch., J. A. Scheel and H. Bauer (1979) Maximum leaf diffusive conductance in vascular plants. Photosythetica 13, 45-82.

Latta, R. P. and B. J. Eaton (1975) Season fluctuations in cannabinoid content of Kansas marijuana. Econ. Bot. 29, 153-166.

Mahlberg, P. G., C. T. Hammond, J. C. Turner and J. K. Hemphill (1984) Structure, development and composition of glandular trichomes of Cannabis sativa L. In Biology and Chemistry of Plant Trichomes (Edited by E. Rodriguez, P. L. Healy and I. Mehta), pp. 23-51. Plenum Press, New York.

Mechoulam, R. (1970) Marijuana chemistry. Science
168, 1159-1166.

Mirecki, R. M. and A. H. Teramura (1984) Effects of ultraviolet-B irradiance on soybean. $V$. The dependence of plant sensitivity on the photosynthetic photon flux density during and after leaf expansion. Plant Physiol. 74, 475-480.

Mobark, Z., D. Bieniek and F. Korte (1978) Some chromatographic aspects of hashish analysis. II. Forensic Sci. 11, 189-193.

Nobel, P. S. (1976) Photosynthetic rates of sun vs shade leaves of Hyptis emoryi (Torr.) Watts. Plant Physiol. 59, 795-799.

Pate, D. W. (1983) Possible role of ultraviolet radiation in evolution of Cannabis chemotypes. Econ. Bot 37, 396-405.

Shoyama, Y., H. Hirano and I. Nishioka (1984) Biosynthesis of propyl cannabinoid acid and its biosynthetic relationship with phenyl and methyl cannabinoid acids. Phytochemistry 23, 1909-1912.

Teramura, A. H. (1983) Effects of ultraviolet-B radiation on the growth and yield of crop plants. Physiol. Plant. 58, 415-427.

Turner, C. E., H. N. Elsohly and G. S. Lewis (1982) Constituents of Cannabis sativa L., XX: The cannabinoid content of Mexican variants grown in Mexico and in Mississippi, United States of America. Bull. Narc. 34, 45-59.

Turner, C. E., P. C. Cheng, G. S. Lewis, M. H. Russell and G. K. Sharma (1979) Constituents of Cannabis sativa XV: Botanical and chemical profile of Indian variants. Planta Med. 37, 217-225.

Turner, C. E., P. S. Fetterman, K. W. Hadley and J. E. Urbanek (1975) Constituents of Cannabis sativa L. $X$. Cannabinoid profile of a Mexican variant and its possible correlation to pharmacological activity. Acta Pharm. Jugoslav. 25, 7-15. 